\title{
Association between neighborhood health behaviors and body mass index in Northern Norway: evidence from the Tromsø Study
}

\author{
EMRE SARI ${ }^{1,2}$ iD, MIKKO MOILANEN ${ }^{2}$, CLARE BAMBRA $^{3}$ iD, \\ SAMELINE GRIMSGAARD ${ }^{4} \&$ INGER NJØLSTAD ${ }^{4}$
}

${ }^{1}$ UiT the Arctic University of Norway, ${ }^{2}$ Vrije University Amsterdam, ${ }^{3}$ Faculty of Medical Sciences, Newcastle University, UK, and ${ }^{4}$ Department of Community Medicine, UiT The Arctic University of Norway, Norway

\begin{abstract}
Aim: The prevalence of overweight and obesity has risen rapidly worldwide, and the ongoing obesity pandemic is one of the most severe public health concerns in modern society. The average body mass index (BMI) of people living in Northern Norway has also steadily increased since the late 1970s. This study aimed to understand how individuals' health behavior is associated with the general health behavior of the people in their neighborhood. Methods: Using the population-based Tromsø Study, we examined the life course association between average leisure time physical activity at the neighborhood level and the BMI of individuals living in the same neighborhood. We used a longitudinal dataset following 25,604 individuals living in 33 neighborhoods and performed a linear mixed-effects analysis. Results: The results showed that participants living in neighborhoods whose residents were more physically active during their leisure time, were likely to have a significantly lower BMI $\left(-0.9 \mathrm{~kg} / \mathrm{m}^{2}, 95 \%\right.$ CI -1.5 to -0.4$)$. Also, individuals living in neighborhoods whose residents were doing mainly manual work, had significantly higher BMIs $\left(0.7 \mathrm{~kg} / \mathrm{m}^{2}, 95 \%\right.$ CI $\left.0.4-1.0\right)$. Conclusions: Our results showed a strong association between the average leisure time physical activity level of neighborhood residents and the higher BMI levels of residents of the same neighborhood.
\end{abstract}

Keywords: Obesity, overweight, body mass index, health behavior, residence characteristics, leisure activities, exercise, health risk behaviors, Norway, longitudinal studies

\section{Background}

Overweight and obesity are on the rise across the world, and their combined effect has emerged as one of the most severe public health issues facing modern society. Obesity is known to have a complex pathology, with evidence of numerous underlying causes. One of many factors that influences the pathway to obesity is the relationship between a neighborhood's socioeconomic conditions and its residents' risky health behaviors [1].

The imbalance between calorie intake and burning formed by behavioral risk factors such as a poor diet, a sedentary lifestyle, or unhealthy habits is one of the primary causes of a high body mass index (BMI) for both overweight $\left(25 \mathrm{~kg} / \mathrm{m}^{2} \geqslant \mathrm{BMI}<30 \mathrm{~kg} / \mathrm{m}^{2}\right)$ and obesity $\left(\mathrm{BMI} \geqslant 30 \mathrm{~kg} / \mathrm{m}^{2}\right)$ [2]. Overweight and obesity are important risk factors of non-communicable diseases such as diabetes, musculoskeletal disorders, obstructive sleep apnea, and some types of cancer (prostate, colorectal, endometrial, and breast) [3].

The mechanisms underlying BMI have been explored in various ways in economics, epidemiology, sociology, medicine, and geography [4]. The effect of a neighborhood's physical and social structure on the lives of the residing individuals is considered to be one of these mechanisms. In the literature, neighborhood effects refer to various neighborhood circumstances, such as the characteristics of individuals

Correspondence: Emre Sari, School of Business and Economics, Vrije University Amsterdam, De Boelelaan 1105, Amsterdam, 1081 HV, Netherlands.

E-mail: emre.sari@uit.no

Date received 14 October 2021; accepted 27 October 2021 
living in the same areas that influence residents' wellbeing [5]. Galster categorizes the "neighborhood effect" theory broadly under four mechanisms: social interaction, environmental, geographical, and institutional [6]. In another major study, Durlauf emphasizes that both role models and peer group influences often produce imitation behavior contemporaneously or across age groups [7]. In this study, we concentrated on social-interactive mechanisms.

We studied whether the higher BMI levels of neighborhood residents were associated with the average leisure time physical activity level of the same neighborhood residents. Several studies, using longitudinal data provide important evidence that the socioeconomic and physical characteristics of the environment in which individuals live influence their BMIs [8-11]. Among these, one of the studies for Norway is Sund et al.'s study [11]. They use the two waves of the Nord-Trøndelag Health Study to examine relationships between area, family, and individual characteristics with BMI and BMI change. However, to our knowledge, no longitudinal studies have previously been used to investigate the relationship between overall neighborhood health behaviors and individual-level BMI.

Our study, therefore, makes a contribution to the international literature by longitudinally examining how the average leisure time physical activity of residents in a neighborhood is associated with the BMI of individuals living in that neighborhood.

\section{Methods}

\section{The Tromsø Study}

The Tromsø Study is a cohort study involving residents of the municipality of Tromsø, which is the largest city in Northern Norway, with around 77,000 inhabitants. The study was first initiated in 1974 to help reduce the high cardiovascular disease (CVD)caused mortality rates in Norway. In addition to identifying causes of high CVD mortality and supporting CVD prevention, it has also focused on other chronic diseases and conditions. In general, the Tromsø Study has comprises the following: demographics; questionnaire; interview; physical examinations such as measured weight, and height, blood pressure, and various types of blood samples; and some other clinical examinations [12]. The Troms $\varnothing$ Study was performed in seven waves (referred to as Tromsø 1-7) from 1974 to 2016 and had a participation rate ranging from $64.7-78.5 \%$. It was funded by UiT The Arctic University of Norway [12].

In our study, we used six waves of the Tromsø Study:Tromsø 2 in 1979/80 $(N=16,621$; age group: 20-54), Tromsø 3 in 1986/87 $(N=21,826$; age group: 12-67), Tromsø 4 in 1994/95 $(N=27,158$; age group: 25-97), Tromsø 5 in 2001/02 $(N=8,130$; age group: 30-89), Tromsø 6 in 2007/08 ( $N=$ 12,984; age group: 30-87), and Tromsø 7 completed in 2015/16 ( $N=21,083$; age group: 40 and older) [12]. We generated longitudinal data by tracing individuals who had participated in at least two waves of the Tromsø Study. In the final dataset, we included 25,604 unique individuals residing in 33 different constituencies. To define the neighborhoods in our article, we used constituency-level information for each individual [11]. In Figure 1, we present the total sample size of each neighborhood.

\section{Variables}

Outcome. Our health outcome was defined as an individual's BMI $[1,4,9,11]$. The BMI is one method used to identify overweight and obesity in individuals [13]. The BMI of each individual in our study was calculated by generating a function of the participants' weight in kilograms divided by the square of his or her height in meters $\left(\mathrm{kg} / \mathrm{m}^{2}\right)$. According to the World Health Organization (WHO), adults with BMI values less than $18.5 \mathrm{~kg} / \mathrm{m}^{2}$ are classified as underweight; adults with BMI values between 18.5 and 24.9 are classified as normal weight; adults with BMI values between 25 and 29.9 are classified as overweight, and adults with a BMI above 30 are classified as obese.

Individual-level explanatory variables. We used the levels of leisure time physical activity reported by the Tromsø Study participants to classify sedentary health behavior $[1,11,14]$. The question was, "Describe your exercise and physical exertion in leisure time over the last year. If your activity varies throughout the year, give an average." The answers were grouped under four levels: (a) reading, watching $\mathrm{TV} / \mathrm{screen}$, or other sedentary activity (reference category); (b) an activity that requires walking or cycling; (c) participation in recreational sports; (d) participation in hard training or sports competitions.

Additionally, we included individual-level demographic, socioeconomic status (SES), and health behavior variables for Tromsø 2-7 (see Table I). Age and age squared were modeled as continuous variables, with both centered on their mean in years [11]. Gender was modeled as a dummy variable [8], and women were used as the reference category. Marital status was classified into three groups: unmarried (reference category), married/registered partnership, and divorced/widow(er)/separated. The SES variables were self-reported and based on both the participants' education level and occupational status as well as their mothers' educational level. We divided the 


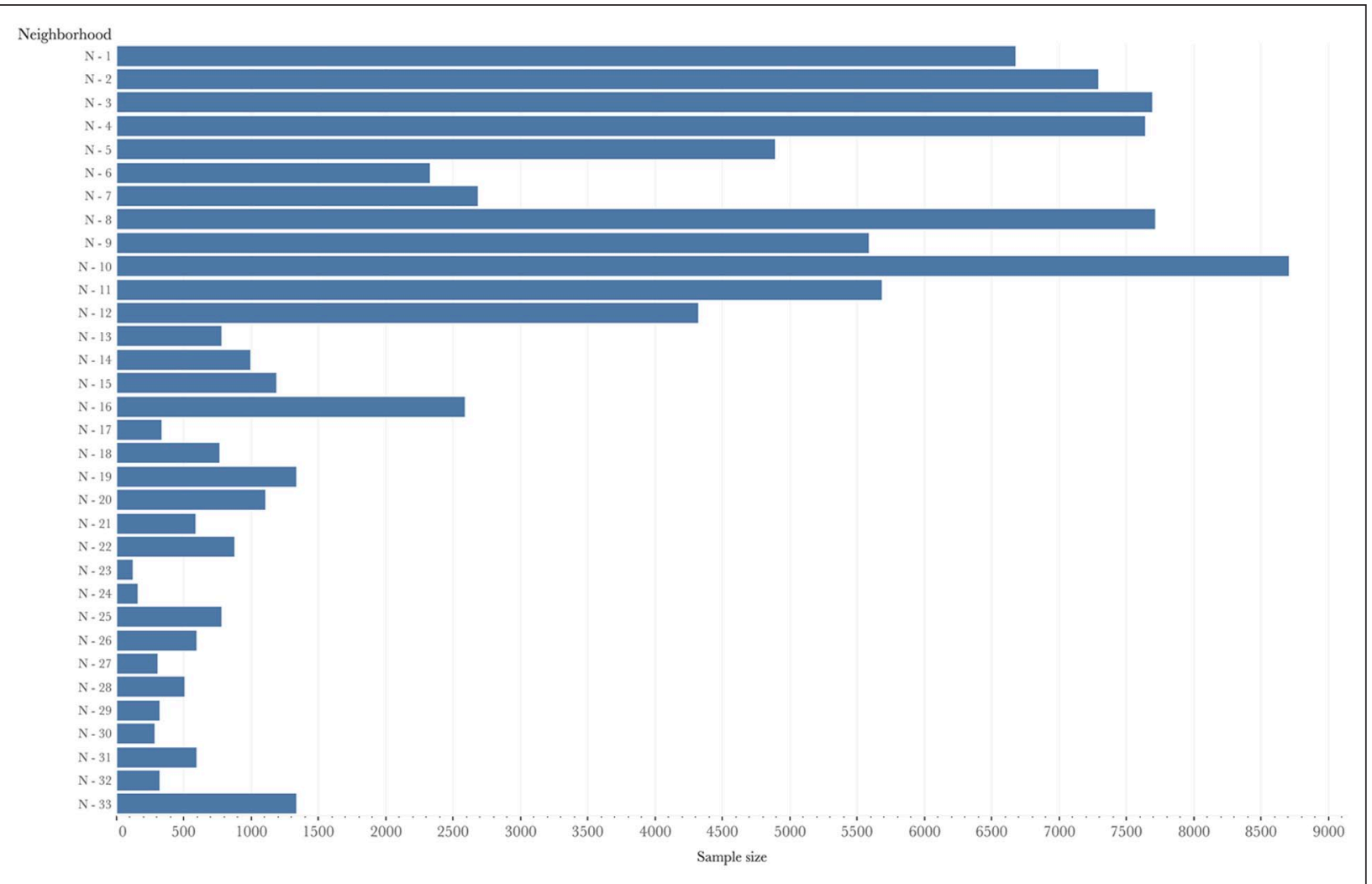

Figure 1. Total sample size of each neighborhood.

Depending on the neighborhood, the distribution of our total sample varies. The sample sizes are presented on the $\mathrm{x}$-axis, and the neighborhoods are shown on the y-axis.

education variables into high (completed 4 years or more at a college/university degree), medium (having a high/technical school diploma), and low (completed an elementary school or no education) as a reference category [8]. Additionally, in order to see the effect of working requirements, we used occupational status like Sund et al. [11] and considered occupational status variables, that is, unemployed/ retired, blue-collar, and white-collar occupations, as proxy measures for physical activity levels during work. The question asked in the surveys was, "If you have paid or unpaid work, which statement describes your work best?" and the answers were arranged in four levels from entirely sedentary work (white-collar worker) to heavy manual labor (blue-collar worker). It is generally accepted that white-collar work requires more mental and less physical effort than blue-collar work [15].

Neighborhood-level explanatory variables. With the intention to investigate how neighborhood health behavior is associated with individual health (represented here by BMI), this study focused on interactive social mechanisms by using neighborhood-level leisure time physical activity as neighborhood-level health behavior. We refer to social contagion, collective socialization, and social networks as endogenous social processes within the interactive social mechanisms. However, we examined the average physical activity level of neighborhood residents at work and respondents' urban-rural segregation with a view to controlling institutional and geographical mechanisms, respectively (for an extensive explanation of mechanisms, see Galster [6]). Neighborhood-level leisure time physical activity and physical activity at work were derived by averaging the individual participant responses for each neighborhood in Tromsø 2-7 [16].

Statistical analyses. We performed a linear mixedeffects (LME) analysis of the relationship between individual $\mathrm{BMI}$ and the average leisure time physical activity level of the neighborhood $[8,11]$. The LME models distinguished the individual- and neighborhood-level sources of variation in BMI and facilitated simultaneous examination of their effects separately. Additionally, for longitudinal data, LME allowed us to detect both variations between individuals and inter-group differences (variations among higherlevel units), as well as estimates of change for single 
Table I. Sample Characteristics.

\begin{tabular}{|c|c|c|c|c|c|c|c|c|c|c|c|c|}
\hline & \multicolumn{2}{|c|}{$\begin{array}{l}\text { Tromsø 2 } \\
(1979-80)\end{array}$} & \multicolumn{2}{|c|}{$\begin{array}{l}\text { Tromsø } 3 \\
(1986-87)\end{array}$} & \multicolumn{2}{|c|}{$\begin{array}{l}\text { Tromsø } 4 \\
(1994-95)\end{array}$} & \multicolumn{2}{|c|}{$\begin{array}{l}\text { Tromsø 5 } \\
(2001-02)\end{array}$} & \multicolumn{2}{|c|}{$\begin{array}{l}\text { Tromsø } 6 \\
(2007-08)\end{array}$} & \multicolumn{2}{|c|}{$\begin{array}{l}\text { Tromsø } 7 \\
(2015-16)\end{array}$} \\
\hline & $N$ & $\begin{array}{l}\text { Mean } \\
(\%)\end{array}$ & $N$ & $\begin{array}{l}\text { Mean } \\
(\%)\end{array}$ & $N$ & $\begin{array}{l}\text { Mean } \\
(\%)\end{array}$ & $N$ & $\begin{array}{l}\text { Mean } \\
(\%)\end{array}$ & $\boldsymbol{N}$ & $\begin{array}{l}\text { Mean } \\
(\%)\end{array}$ & $N$ & $\begin{array}{l}\text { Mean } \\
(\%)\end{array}$ \\
\hline \multicolumn{13}{|l|}{ Individual level } \\
\hline Body mass index & 12,985 & $\begin{array}{c}23.51 \\
(3.19)\end{array}$ & 17,952 & $\begin{array}{l}23.96 \\
(3.35)\end{array}$ & 21,113 & $\begin{array}{c}25.18 \\
(3.77)\end{array}$ & 7690 & $\begin{array}{c}26.61 \\
(4.24)\end{array}$ & 12,133 & $\begin{array}{c}26.90 \\
(4.26)\end{array}$ & 15,143 & $\begin{array}{c}27.34 \\
(4.45)\end{array}$ \\
\hline Age (years) & 12,985 & $\begin{array}{l}34.97 \\
(8.80)\end{array}$ & 17,952 & $\begin{array}{l}38.53 \\
(10.43)\end{array}$ & 21,113 & $\begin{array}{l}45.88 \\
(12.35)\end{array}$ & 7690 & $\begin{array}{c}60.52 \\
(13.35)\end{array}$ & 12,133 & $\begin{array}{c}58.23 \\
(12.30)\end{array}$ & 15,143 & $\begin{array}{c}61.15 \\
(10.22)\end{array}$ \\
\hline \multicolumn{13}{|l|}{ Sex } \\
\hline Females (ref) & 6379 & 49.1 & 8951 & 49.9 & 10,999 & 52.1 & 4384 & 57.0 & 6496 & 53.5 & 8071 & 53.3 \\
\hline Males & 6606 & 50.9 & 9001 & 50.1 & 10114 & 47.9 & 3306 & 43.0 & 5637 & 46.5 & 7072 & 46.7 \\
\hline \multicolumn{13}{|l|}{ Marital Status } \\
\hline Unmarried (ref) & 3303 & 25.4 & 5252 & 29.3 & 5272 & 25.0 & 1086 & 14.1 & 2011 & 16.6 & 2798 & 18.5 \\
\hline Married/registered partnership & 8950 & 68.9 & 11,022 & 61.4 & 12,501 & 59.2 & 4772 & 62.1 & 7310 & 60.2 & 8950 & 59.1 \\
\hline Divorced/widow(-er)/separated & 732 & 5.6 & 1677 & 9.3 & 3340 & 15.8 & 1832 & 23.8 & 2812 & 23.2 & 3395 & 22.4 \\
\hline \multicolumn{13}{|l|}{ Education } \\
\hline Low (ref) & 6619 & 58.5 & 8105 & 48.9 & 7083 & 33.7 & 4210 & 57.3 & 3525 & 29.5 & 4094 & 27.6 \\
\hline Moderate & 3947 & 34.9 & 6885 & 41.5 & 7887 & 37.5 & 2350 & 32.0 & 4039 & 33.8 & 7049 & 47.6 \\
\hline High & 752 & 6.6 & 1593 & 9.6 & 6072 & 28.9 & 787 & 10.7 & 4402 & 36.8 & 3678 & 24.8 \\
\hline \multicolumn{13}{|l|}{ Mothers' education } \\
\hline Low (ref) & 7067 & 87.7 & 9843 & 84.4 & 12,130 & 82.1 & 4461 & 85.3 & 9266 & 80.1 & 11,642 & 78.2 \\
\hline Moderate & 840 & 10.4 & 1529 & 13.1 & 2194 & 14.9 & 629 & 12.0 & 1715 & 14.8 & 2629 & 17.7 \\
\hline High & 147 & 1.8 & 288 & 2.5 & 449 & 3.0 & 137 & 2.6 & 583 & 5.0 & 616 & 4.1 \\
\hline \multicolumn{13}{|l|}{ Occupation } \\
\hline Unemployed or retired (ref) & 394 & 3.0 & 583 & 3.2 & 700 & 3.3 & 60 & 0.8 & 52 & 0.4 & 1493 & 9.9 \\
\hline White-collar worker & 4289 & 33.0 & 6916 & 38.5 & 7107 & 33.7 & 1966 & 25.6 & 4084 & 33.7 & 5852 & 38.6 \\
\hline Blue-collar worker & 8302 & 63.9 & 10,453 & 58.2 & 13,306 & 63.0 & 5664 & 73.7 & 7997 & 65.9 & 7798 & 51.5 \\
\hline \multicolumn{13}{|l|}{ Physical activity at leisure times } \\
\hline Mostly sedentary activity (ref) & 2679 & 20.7 & 4140 & 23.1 & N/A & N/A & 1025 & 19.7 & 2252 & 20.2 & 2050 & 14.1 \\
\hline Activity that requires walking or cycling & 7209 & 55.6 & 10,492 & 58.5 & N/A & N/A & 3402 & 65.5 & 6674 & 60.0 & 8791 & 60.4 \\
\hline Participation in recreational sports & 2656 & 20.5 & 2865 & 16.0 & N/A & $\mathrm{N} / \mathrm{A}$ & 694 & 13.4 & 2023 & 18.2 & 3358 & 23.1 \\
\hline $\begin{array}{l}\text { Participation in hard training or sports } \\
\text { competitions }\end{array}$ & 427 & 3.3 & 447 & 2.5 & N/A & N/A & 70 & 1.3 & 173 & 1.6 & 351 & 2.4 \\
\hline \multicolumn{13}{|l|}{ Neighborhood level } \\
\hline Physical Activity at leisure times & 12,985 & $\begin{array}{c}2.06 \\
(0.06)\end{array}$ & 17,952 & $\begin{array}{c}2.02 \\
(0.06)\end{array}$ & $\mathrm{N} / \mathrm{A}$ & N/A & 7690 & $\begin{array}{c}1.97 \\
(0.06)\end{array}$ & 12,133 & $\begin{array}{c}2.01 \\
(0.06)\end{array}$ & 15,143 & $\begin{array}{c}2.16 \\
(0.07)\end{array}$ \\
\hline Physical activity at work & 12,985 & $\begin{array}{c}1.98 \\
(0.23)\end{array}$ & 17,952 & $\begin{array}{c}1.89 \\
(0.20)\end{array}$ & 21,113 & $\begin{array}{c}1.93 \\
(0.25)\end{array}$ & 7690 & $\begin{array}{c}1.80 \\
(0.23)\end{array}$ & 12,133 & $\begin{array}{c}1.73 \\
(0.22)\end{array}$ & 15,143 & $\begin{array}{c}1.66 \\
(0.18)\end{array}$ \\
\hline \multicolumn{13}{|l|}{ Type of neighborhood } \\
\hline Urban (ref) & 10,792 & 83.1 & 12,698 & 70.7 & 18,376 & 87.0 & 6692 & 87.0 & 10,776 & 88.8 & 12,181 & 80.4 \\
\hline Rural & 2193 & 16.9 & 5254 & 29.3 & 2737 & 13.0 & 998 & 13.0 & 1357 & 11.2 & 2962 & 19.6 \\
\hline
\end{tabular}

Note: BMI classification is as follows: $\mathrm{BMI}<18.5 \mathrm{~kg} / \mathrm{m}^{2}$ is underweight, $18.5 \mathrm{~kg} / \mathrm{m}^{2} \geqslant \mathrm{BMI}<25 \mathrm{~kg} / \mathrm{m}^{2}$ is normal weight, $25 \mathrm{~kg} / \mathrm{m}^{2} \geqslant \mathrm{BMI}<30 \mathrm{~kg} / \mathrm{m}^{2}$ is overweight, $30 \mathrm{~kg} / \mathrm{m}^{2} \geqslant \mathrm{BMI}$ is obesity. Education level is classified under three levels: low education postulates 7-10 years primary/secondary school and modern secondary school; moderate education covers high school and technical school diploma; and high education represents college/university or more. Urban and rural differentiation was done by using the classification in Hopstock et al.[17] Neighborhood-level variables were manually generated by the average results of individuals who lived in the same neighborhood.

individuals. The fundamental and methodological importance of LME models has been defined comprehensively in literature $[11,18,19]$.

In our study, we estimated two-level models with the continuous responses of BMI for individuals (Level 1) nested within neighborhoods (Level 2). We used restricted maximum likelihood to estimate the model parameters [18], and fitted them by using the lme4 v1.1-25 package [20]. By following Sund et al. [11], first, we developed a model (Model A/1) that was fitted with a null (empty) model to determine the variation in outcome between the two levels. Second, we included individual-level demographics (age, age squared, gender, and marital status) and the year of each Tromsø Study as control (Model A/2). Third, we included SES variables (Model A/3): education, mother's education, and occupation. Fourth, we entered leisure time physical activity level of the neighborhood residents (Model A/4). Lastly, in addition to individual-level control variables, we entered neighborhood-level variables (Model A): mean physical activity level during leisure time, mean physical activity level at work, and the urban-rural divide. In addition, we separated the models into two categories: fixed effects and random effects. Fixed effects are predictor variables whose effects do not vary 
between individuals and neighborhoods. The variance in outcome at the individual and neighborhood levels that remains after controlling for the fixed effects are the random effects [11]. Finally, we developed a second model (Model B), a subgroup of Model A, which included only individuals observed in the same neighborhood throughout the Tromsø Study waves to control our results' robustness.

LME models are flexible enough to deal with unbalanced data [21], such as the data we used in this study. However, to be on the safe side, we tested our model's outputs with Kenward-Roger's $F$ test to assess the significance of the fixed effects [22], and found the same significance levels for the same variables. We also conducted the variance inflation factor (VIF) analysis to check the probability of multicollinearity risk in our models. The results of the VIF analysis varied from 1.019 to a maximum of 3.416 ; the only exceptions were age, age squared, and time, as expected. Therefore, we determined that multicollinearity was not a risk factor in our models since the results were close to the smallest possible value for VIF [23]. Finally, we used the intraclass correlation coefficient (ICC) to report variations among higherlevel units. In the model, we determined with ICC the percentage of total unexplained variance for each level. The results are presented in Table II below.

\section{Results}

\section{Descriptive characteristics}

Table I presents the characteristics of the neighborhood- and individual-level variables. Mean BMI increased constantly from Tromsø 2 to Tromsø 7, in line with the previous studies conducted in Troms $\varnothing$ [24]. We observed that this situation could raise the mean BMI limits from a normal weight to the overweight level. Furthermore, the average BMI of people living in the same neighborhood throughout the Tromsø Study surveys differed significantly from that of those living in different neighborhoods (Figure 2).

The mean age in Tromsø 2 was 35 years and, due to the sample panel structure, it steadily increased up to 61.15 years in Tromsø 7 . Females accounted for $52 \%$ of our sample, but the rate of participation by gender varied between studies. The majority of the participants were married and living in an urban area. The variables related to SES indicate that the education level of participants changed from survey to survey; we also observed that the educational level of the participants' mothers mostly fell within the low category ( $81 \%$ on average). Based on age, the number of unemployed or retired participants increased in Tromsø 7, while blue-collar workers decreased.
Appendix A presents the descriptive characteristics of those included in Model B.

\section{Association between neighborhood health behaviors and body mass index in Northern Norway}

Table II summarizes the coefficients and ICC values for both models via regression from the unconditional model to explanatory variables. The null model, Model A/1, showed that approximately $68 \%$ of BMI variation was at the individual level, and $21 \%$ occurred between neighborhoods. After controlling for sample demographics (Model A/2), we saw a quadratic relationship with age and found that BMI values were higher among middle-aged participants but lower among older and younger participants. In addition, individuals who reported their marital status as married/registered partnership and divorced/ widow(-er)/separated were more likely to have a lower BMI (respectively, $-0.219 \mathrm{~kg} / \mathrm{m}^{2}, 95 \%$ confidence interval (CI) -0.282 to $-0.156 ;-0.306 \mathrm{~kg} / \mathrm{m}^{2}$, $95 \%$ CI -0.385 to -0.228$)$ than those who did not have a relationship or reported that they had never been married. Also, we found that the participants' BMI increased significantly from Tromsø 3 to Tromsø 7 compared with Tromsø 1. Incorporating the SES variables (Model A/3) showed higher BMI among respondents reporting low education. Additionally, we showed that participants who reported higher maternal education had a lower BMI $\left(-0.593 \mathrm{~kg} / \mathrm{m}^{2}, 95 \%\right.$ CI -0.862 to -0.323$)$. Interestingly, maternal education level was more influential than both the moderate $\left(-0.101 \mathrm{~kg} / \mathrm{m}^{2}\right.$, $95 \% \mathrm{CI}-0.159$ to -0.043$)$ and high education levels $\left(-0.292 \mathrm{~kg} / \mathrm{m}^{2}, 95 \%\right.$ CI -0.373 to -0.211$)$ of the participants. Also, being a blue-collar worker was significantly associated with a lower BMI than nonworking people.

In Model $\mathrm{A} / 4$, the addition of the individual-level behavioral variable showed that those participants who were physically active during their leisure times had significantly lower BMI values $\left(-0.913 \mathrm{~kg} / \mathrm{m}^{2}\right.$, $95 \% \mathrm{CI}-1.077$ to -0.750$)$. Furthermore, after controlling for physical activity during leisure time, the BMI association between white-collar workers and non-working individuals was in the same direction and significant $\left(-0.114 \mathrm{~kg} / \mathrm{m}^{2}, 95 \% \mathrm{CI}-0.232\right.$ to $-0.004)$; it was not at the same level as in the case of blue-collar workers. After accounting for all neighborhood-level variables, Model A showed that individual-level BMI was significantly associated with the overall health behaviors detected in the same neighborhood - in addition to the effects of individuals' own physical activity. We found that BMI values 
E. Sari et al.

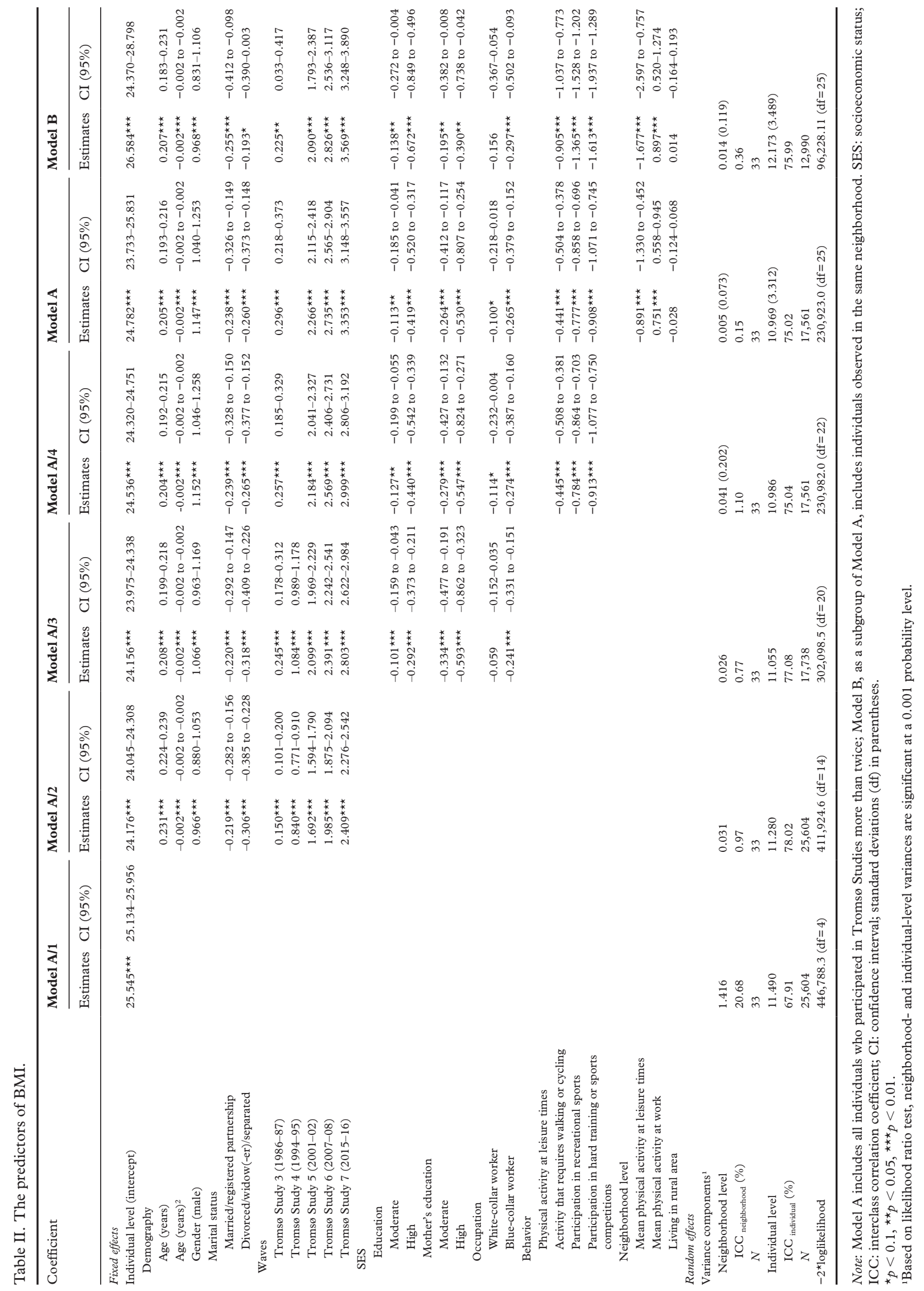



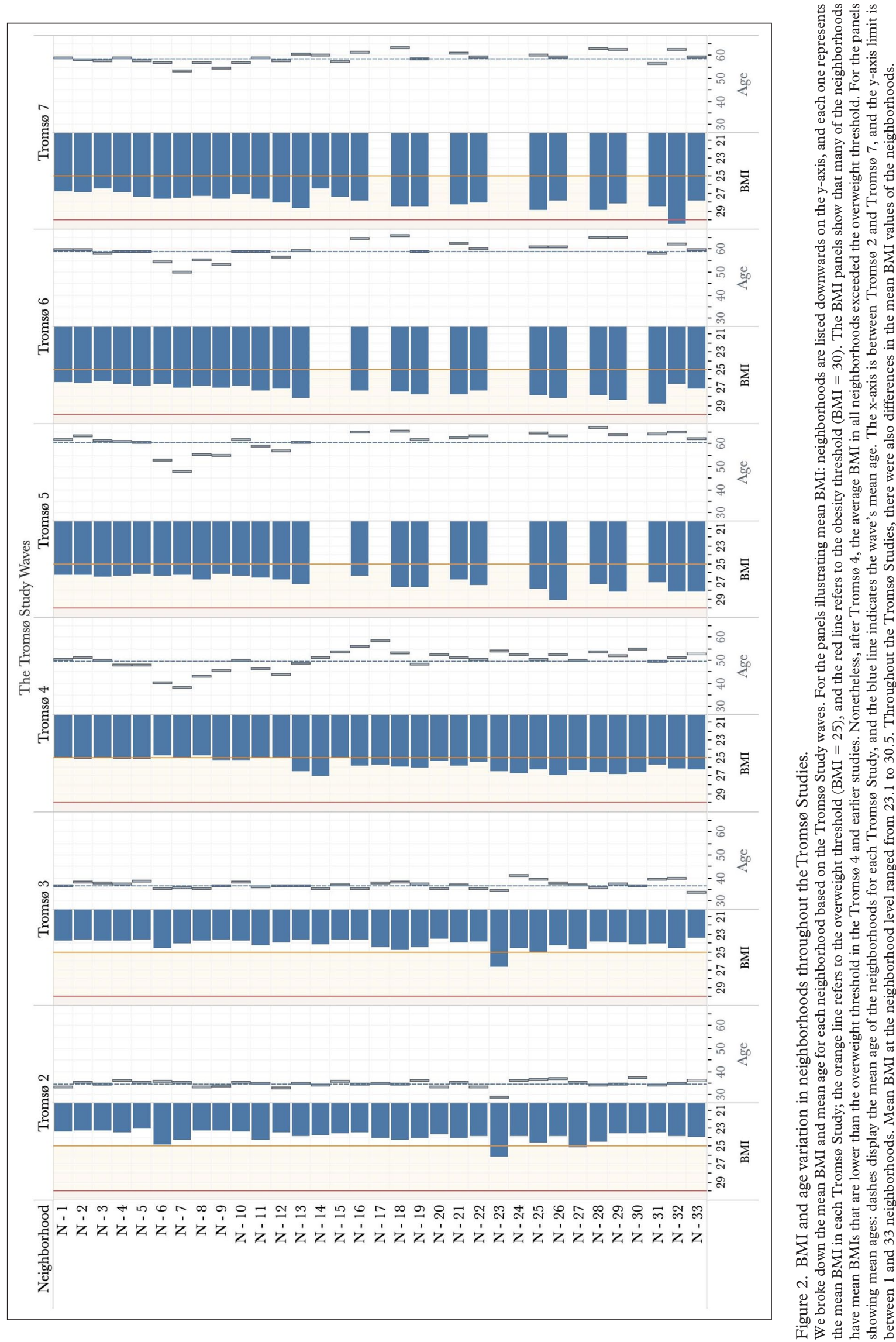
$\left(-0.891 \mathrm{~kg} / \mathrm{m}^{2}, 95 \% \mathrm{CI}-1.330\right.$ to -0.452$)$ of participants were progressively lower for participants living in neighborhoods with more physically active populations. Another significant result was that individuals in neighborhoods where inhabitants were mostly employed in jobs requiring manual work, had a higher BMI on average $\left(0.751 \mathrm{~kg} / \mathrm{m}^{2}, 95 \% \mathrm{CI}\right.$ 0.558 to 0.945 ) than individuals in other neighborhoods. We found no evidence of an association between the urban or rural characteristics of neighborhoods, and the BMI values of their residents.

In Model B, we narrowed our sample group to individuals living in the same neighborhood. The Model B results shown in Table II are generally in line with our findings in Model A. However, when we focus on average leisure time physical activity level in the neighborhoods, the association of neighborhood health behavior was almost twice as high as the Model A results $\left(-1.677 \mathrm{~kg} / \mathrm{m}^{2}, 95 \%\right.$ CI -2.597 to $-0.757)$. We also saw the same double association on the individual-level variable of physical activity during leisure times, which varied from simple walking to strenuous training activities compared with a sedentary lifestyle. Under this model, taken independently, we found no significant evidence of a BMI association between white-collar workers and nonworking individuals.

\section{Discussion}

In this study, we examined the association between the average leisure time physical activity level of the neighborhood and BMI in a comprehensive longitudinal sample of adult individuals from Northern Norway. The most important finding that emerged from this study was that the overall leisure time physical activity level of the neighborhood was associated with the individual-level BMI values in the same neighborhood. This finding is consistent with Durlauf's explanation of imitation behavior, assuming that an individual will find a particular behavior comparatively more desirable when evaluating alternative behavioral choices if others have previously behaved or are currently behaving the same way [7]. In addition, as Sund et al. point out, some characteristics of the neighborhood's social or physical environment may also be relevant in weight gain [11]

The second significant finding was that people who live in neighborhoods where people work in labor-intensive jobs have higher BMI values than others, regardless of labor activity. Sund et al.'s finding that physically demanding workers gain more weight than others at the neighborhood level but not at the individual level [11] is supported by our results. As they discussed, this is attributable to manual workers' reduced leisure time physical activity and their less desirable dietary habits outside of the workplace [11]. Furthermore, education is important in relation to gaining awareness about poor diets and sedentary lifestyles that can have an adverse impact on BMI [11,25]. Furthermore, we showed that a mother's level of education affected an individual's BMI, with stronger effects observed in individuals with higher maternal education.

Although some studies show that the neighborhood is significantly associated with BMI $[8,9]$, other studies conclude that environmental conditions do not affect BMI [4]. The former studies draw on the idea that the characteristics of residential areas can promote salutogenic or pathogenic health behaviors of their residents through exposure to factors such as area-level unemployment and access to social and physical resources such as food, healthcare, and green space [26]. For example, a study conducted in the USA found that people living in less deprived areas were more physically active since those areas had enough facilities available to allow for physical activities [10]. Moreover, residents of areas with a higher density of fast-food outlets have lower rates of fruit and vegetable consumption, and food desert and obesogenic environments increase excessive food intake [25].

Our study includes both strengths and limitations. One of the advantages is the availability of data from a large, well-characterized cohort of individuals for an extended period. The relationship between BMI and obesity and overweight is well established in the literature $[4,8,11,13]$. Anthropometric measurements such as waist circumference are also used in obesity studies $[14,27]$. Since BMI is the most useful measure of overweight and obesity at the population level, we used BMI and calculated it using WHOrecommended height and weight measurements [13]. Because of the large sample size and data availability, we were able to investigate the effects of neighborhoods. By correctly assigning individuals to these neighborhoods both in time and geography, we were able to generate a continuous contextual exposure from Tromsø 2 to 7 , which covers 37 years. Other studies have also emphasized the significance of understanding the many levels in a population, noting that ignoring one level will alter estimates at other levels $[11,19]$.

The major limitation of this study was that our neighborhood level consists of data from specific years of the Tromsø Studies. During the gap years, individuals were likely to move between/within neighborhoods or outside of the Tromsø municipality, and there were no available records of their residential areas in the Tromsø Study. Since it was possible that 
movers who relocated within the Tromsø municipality either relocated to areas that resembled their previous neighborhoods or to neighborhoods with higher/lower SES [28], we might have missed the influence of these movers in our results. Considering this possibility, we repeated our analysis only for the individuals who were observed in the same neighborhood to provide a stable sample for estimating neighborhood effect (see Model B) [4,11]. The dataset in our study, on the other hand, was made up of people who lived in a single county. As a result, even after accounting for rural and urban differences, the variability in the physical environment was limited. In addition, individuals may tend to overstate leisure time physical activity levels, which may have introduced bias and diluted its relationship with BMI [14]; nonetheless, the relationship between selfreported leisure time physical activity level and chronic diseases is well established [27]. According to Rödjer et al., self-reported leisure time physical activity level is associated with the presence of several cardiovascular risk factors [27]. Finally, it is worth noting that some of the participants were likely to be members of the same biological family, and genetic information, as well as family environment characteristics, may have an impact on weight gain [29].

Apart from neighborhood effects being academically intriguing, its concept has been utilized by policymakers for reducing the potential of adverse neighborhood effects [30]. Our findings indicated that individuals' BMI differed in the context of a neighborhood, implying that regional policymakers should consider not only the physical or socioeconomic conditions of the neighborhood but also how to improve the overall health behaviors of the people who live there. As Sundquist et al. [31] stated, multidisciplinary interactions between health researchers, city planners, economists, and policymakers are required in neighborhood-level strategies; governmental initiatives should incorporate multidimensional correlates of physical activity.

Further studies regarding the role of relocation over time would be worthwhile [11]. Thus, it could be investigated whether individuals choose the neighborhood in which they live because of their health behaviors or whether their health behaviors are affected by overall health behaviors in the area in which they live.

\section{Conclusion}

The present study was designed to determine the relationship between the overall leisure time physical activity level of the neighborhood and the BMI of its residents in a large 37-year panel sample of adults. Taken together, the results suggested that there was an association between neighborhoodlevel variables and residents' BMIs. Specifically, having neighbors who were physically active during their leisure time was associated with lower BMIs.

\section{Acknowledgements}

We are grateful for comments on previous drafts of the paper from conference participants at the Arctic Frontiers 2021 Science and the 43rd Meeting of the Norwegian Association for Economists, and seminar attendants at both the Social Inequality in Health Research Group and the Centre for Economic Research at UiT The Arctic University of Norway.

\section{Declaration of Conflicting Interests}

The authors declared no potential conflicts of interest with respect to the research, authorship, and/or publication of this article.

\section{Funding}

The authors disclosed receipt of the following financial support for the research, authorship, and/or publication of this article: This research project was funded by the High North Population Studies (HighNoPos) project at UiT The Arctic University of Norway. The publication charges for this article were funded by a grant from the Healthy Choices project at UiT The Arctic University of Norway.

The Regional Committee for Medical and Health Research Ethics in Northern Norway provided ethics approval.

\section{ORCID iDs}

Emre Sari (iD https://orcid.org/0000-0001-9805-9227

Clare Bambra (iD https://orcid.org/0000-0002-1294 $-6851$

\section{References}

[1] Cawley J and Ruhm C. The economics of risky health behaviours. Working paper 17081. Natl Bur Econ Res, https://www. nber.org/system/files/working_papers/w17081/w17081.pdf (2011, 15 December 2020).

[2] Chatterjee A, Gerdes MW and Martinez SG. Identification of risk factors associated with obesity and overweight: a machine learning overview. Sensors 2020;20:2734.

[3] Burns J, Conway DI, Gnich W, et al. Linking families with pre-school children from healthcare services to community resources: a systematic review protocol. Syst Rev 2017;6:50.

[4] Ou S. Are some neighborhoods bad for your waistline? A test of neighborhood exposure effects on BMI. F Health Econ 2019;63:52-63.

[5] Roosa MW and White RMB. Neighborhood effects. In: Michalos AC (ed) Encyclopedia of quality of life and well-being research. Dordrecht: Springer, 2014, pp.4328-31. 
[6] Galster GC. The mechanism(s) of neighbourhood effects: theory, evidence, and policy implications. In: van Ham M, Manley D, Bailey N, Simpson L and Maclennan D (eds) Neighbourhood effects research: new perspectives. Dordrecht: Springer, 2012, pp.23-56.

[7] Durlauf SN. Neighborhood effects. In: Vernon Henderson J and Thisse J-F (eds) Handbook of regional and urban economics. Vol 4. Amsterdam: Elsevier Inc, 2004, Chapter 50.

[8] Jimenez MP, Wellenius GA, Subramanian S V, et al. Longitudinal associations of neighborhood socioeconomic status with cardiovascular risk factors: a 46-year follow-up study. Soc Sci Med 2019;241:112574.

[9] Yang TC and South SJ. Neighborhood effects on body mass: temporal and spatial dimensions. Soc Sci Med 2018;217: $45-54$.

[10] Gordon-Larsen P, Nelson MC, Page P, et al. Inequality in the built environment underlies key health disparities in physical activity and obesity. Pediatrics 2006;117:417-24.

[11] Sund ER, Jones A and Midthjell K. Individual, family, and area predictors of BMI and BMI change in an adult Norwegian population: findings from the HUNT study. $S o c S c i$ Med 2010;70:1194-1202.

[12] Jacobsen BK, Eggen AE, Mathiesen EB, et al. Cohort profile: the Tromsø study. Int $\mathcal{F}$ Epidemiol 2012;41:961-7.

[13] World Health Organization. Obesity and overweight. Fact sheet No. 311. https://www.who.int/en/news-room/fact-sheets/ detail/obesity-and-overweight (2020, accessed 14 November).

[14] Aars NA, Jacobsen BK, Morseth B, et al. Longitudinal changes in body composition and waist circumference by self-reported levels of physical activity in leisure among adolescents: the Tromse study, Fit Futures. BMC Sports Sci Med Rehabil 2019;11:37.

[15] Wu B and Porell F. Job characteristics and leisure physical activity. F Aging Health 2000;12:538-59.

[16] Waller M, Lissner L, Hange D, et al. Socioeconomic disparities in physical activity among Swedish women and trends over time-the population study of women in Gothenburg. Scand 7 Prim Health Care 2018;36:363-71.

[17] Hopstock L, Løvsletten O, Johansen H, et al. Folkehelserapport: Den sjuende Tromsøundersøkelsen 2015-16. Septentrio Reports 2019:1

[18] Oshchepkov A and Shirokanova A. Multilevel modeling for economists: why, when and how. SSRN Electron F. Published online 2020 , doi: $10.2139 /$ ssrn. 3637907
[19] Tranmer $M$ and Steel DG. Ignoring a level in a multilevel model: evidence from UK census data. Environ Plan $A$ 2001;33:941-8.

[20] Bates D, Mächler M, Bolker BM, et al. Fitting linear mixedeffects models using lme4. I Stat Softw 2015;67:1-48.

[21] Sommet N and Morselli D. Keep calm and learn multilevel logistic modeling: a simplified three-step procedure using Stata, R, Mplus, and SPSS. Int Rev Soc Psychol 2017;30:203-18.

[22] Luke SG. Evaluating significance in linear mixed-effects models in R. Behav Res Methods 2017;49:1494-1502.

[23] Purkayastha A. Performance of business group affiliated firms in emerging markets: causal mediation analysis of internationalization and investment into innovation strategy. Int $\mathcal{F}$ Emerg Mark 2018;13:1538-58.

[24] Renninger M, Løchen ML, Ekelund U, et al. The independent and joint associations of physical activity and body mass index with myocardial infarction: the Tromsø Study. Prev Med (Baltim) 2018;116:94-8.

[25] Burgoine T, Forouhi NG, Griffin SJ, et al. Does neighborhood fast-food outlet exposure amplify inequalities in diet and obesity? A cross-sectional study. Am $\mathcal{F}$ Clin Nutr 2016;103:1540-7.

[26] Bambra C. Health divides: where you live can kill you. 1st ed. Bristol: Bristol University Press, 2016.

[27] Rödjer L, Jonsdottir IH, Rosengren A, et al. Self-reported leisure time physical activity: a useful assessment tool in everyday health care. BMC Public Health 2012;12:693.

[28] Gebremariam MK, Lien N, Nianogo RA, et al. Mediators of socioeconomic differences in adiposity among youth: a systematic review. Obes Rev 2017;18:880-98.

[29] Persky S, Yaremych HE, Megan BA, et al. Investigating the efficacy of genetic, environmental, and multifactorial risk information when communicating obesity risk to parents of young children. Ann Behav Med 2021;55:720-33.

[30] Van Ham M, Manley D, Bailey N, et al. Neighbourhood effects research: new perspectives. In: Neighbourhood effects research: new perspectives. Dordrecht: Springer, 2012, pp.1-21.

[31] Sundquist K, Eriksson U, Kawakami N, et al. Neighborhood walkability, physical activity, and walking behavior: the Swedish Neighborhood and Physical Activity (SNAP) study. Soc Sci Med 2011;72:1266-73. 